\title{
Expression of $\beta 1$ Integrins in Sensory Neurons of the Dorsal Root Ganglion and Their Functions in Neurite Outgrowth on Two Laminin Isoforms
}

\author{
Kevin J. Tomaselli, ${ }^{1,2, a}$ Patrick Doherty, ${ }^{4}$ Caroline J. Emmett, ${ }^{2, b}$ Caroline H. Damsky, ${ }^{3}$ Frank S. Walsh, ${ }^{4}$ and \\ Louis F. Reichardt ${ }^{2}$ \\ 'Athena Neurosciences Inc., South San Francisco, California 94080, ${ }^{2}$ Neuroscience Program, Department of Physiology, \\ and the Howard Hughes Medical Institute, and ${ }^{3}$ Departments of Stomatology and Anatomy, UCSF, San Francisco, \\ California 94143, and ${ }^{4}$ Department of Experimental Pathology, UMDS, Guy's Hospital, London, England SE1 9RT
}

Integrins are heterodimeric receptors that mediate responses of neurons and many other cell types to components of the extracellular matrix. In the present article, we examine the roles of individual integrin receptors expressed by spinal sensory neurons of the dorsal root ganglion (DRG) in mediating interactions with laminin, an extracellular matrix glycoprotein that promotes neurite outgrowth. DRG neurons were shown to express three $\beta 1$ integrins that have been shown in other cell types to function as laminin receptorshigh levels of $\alpha 1 \beta 1$ and $\alpha 3 \beta 1$ and low levels of $\alpha 6 \beta 1$. In addition, DRG neurons were shown to express a known fibronectin receptor, $\alpha 5 \beta 1$, and an integrin with undefined ligands, $\alpha 6 \beta 4$. Function-inhibitory monoclonal antibodies specific for the $\alpha 1, \alpha 2, \alpha 3, \alpha 5$, and $\alpha 6$ integrin subunits were used to determine the roles of individual integrins in mediating neurite outgrowth by DRG neurons on laminin. The results demonstrate that $\alpha 1 \beta 1$ and $\alpha 3 \beta 1$ function as laminin receptors on these neurons.

As many as 18 distinct isoforms of laminin may exist, assembled as heterotrimers containing one each of the different A, B1, or B2 subunit homologs. In the present study, we characterize neurite outgrowth in response to two of these isoforms, the AeB1eB2e isoform and the AmB1eB2e isoform. Results utilizing DRG neurons and a pheochromocytoma cell line (PC12) indicate that these two isoforms exhibit differential selectivities for the $\alpha 1 \beta 1$ and $\alpha 3 \beta 1$ integrins. Thus, $\alpha 1 \beta 1$ functions much less efficiently on the AmB1eB2e isoform than on the AeB1eB2e isoform, while $\alpha 3 \beta 1$ appears to be a more important receptor on $A m B 1 e B 2 e$ than on AeB 1eB2e. Since laminin isoforms are differentially

Received Mar. 2, 1993; revised May 12, 1993; accepted May 20, 1993.

We thank Dr. David Turner for providing mAb $3 \mathrm{~A} 3 \mathrm{IgG}$ and Dr. A. Sonnenberg for $\mathrm{GoH} 3$ hybridoma culture supernatant. We thank Marion Meyerson for typing the manuscript. We also thank Drs. Jim Cohen, Andrew Lumsden, and Janet Winter for helpful discussions during the course of this work. This article is dedicated to the memory of M.F.T. This work was supported by the Wellcome Trust and the Howard Hughes Medical Institute

Correspondence should be addressed to Kevin J. Tomaselli, Neuroscience Program, Department of Physiology and the Howard Hughes Medical Institute, San Francisco, CA 94143-0724.

a Present address: IDUN Pharmaceuticals, 3000 Sand Hill Road, Building 2, Suite 290, Menlo Park, CA 94025.

b Present address: Department of Neurosciences, Institute of Pharmacology, Syntex Inc., Palo Alto, CA 94303.

Copyright (c) 1993 Society for Neuroscience $0270-6474 / 93 / 134880-09 \$ 05.00 / 0$ localized during embryogenesis, these functional differences may be important for neural development.

[Key words: laminin, merosin, integrins, neurite outgrowth, dorsal root ganglion, regeneration]

Laminins comprise a family of related trimeric, multifunctional glycoproteins that are often localized to basement membranes (Engel et al., 1991). The best-characterized laminin, isolated from the Engelbreth-Holm-Swarm (EHS) sarcoma, consists of three glycoprotein subunits, Ae, Ble, and B2e, that are disulfide bonded into a large $\left(\sim 10^{6} \mathrm{Da}\right)$, cruciform structure (Beck et al., 1990). Recently, scveral laminin subunit homologs have been characterized: Am (merosin) and Ak (K-laminin), two A-chain homologs (Leivo and Engvall, 1988; Ehrig et al., 1990; Marinkovich et al., 1992); B1-2 and B1s (S-laminin), which appear to be two Bl chain homologs (Hunter et al., 1989a; O'Rear, 1992); and B2t, a truncated B2 chain homolog (Kallunki et al., 1992). As many as 18 structurally distinct laminin isoforms can potentially be assembled combinatorially from these eight subunits as trimeric structures composed of one A, one Bl, and one B2 homolog (Engvall et al., 1990; Engel et al., 1991). Laminin isoforms are differentially distributed in vivo (Engvall et al., 1990; Sanes et al., 1990), suggesting that laminin isoforms will prove to have different functions. Evidence for functional differences between laminin isoforms containing the B1s or B1e subunits has already been provided by Hunter et al. (1989b), who showed that ciliary motoneurons, but not other types of neurons, interact with bacterial fusion proteins containing frag ments of the B1s subunit.

Laminins are widely expressed in the developing embryo, where they are thought to exert a variety of influences on neurons. In vitro, these include stimulation of neuronal process outgrowth, survival, differentiation, and neurotransmitter phenotype expression (reviewed in Reichardt and Tomaselli, 1991). While it has been known for some time that neuronal attachment and process outgrowth in response to EHS laminin depend on the function of $\beta 1$ integrins (Bozyczko and Horwitz, 1986; Tomaselli et al., 1986), the specific $\alpha \beta 1$ integrins that mediate the responses of primary neurons to laminins are largely unknown. Five of the known $\beta 1$ integrins $-\alpha 1 \beta 1$ (Turner et al., 1989; Hall et al., 1990; Ignatius et al., 1990), $\alpha 2 \beta 1$ (Elices and Hemler, 1989; Languino et al., 1989), $\alpha 3 \beta 1$ (Gehlsen et al., 1989), $\alpha 6 \beta 1$ (Sonnenberg et al., 1988), and $\alpha 7 \beta 1$ (Kramer et al., 1989)-have 
been reported to function in different cell types as receptors for EHS laminin (reviewed in Hemler, 1990; Reichardt and Tomaselli, 1991). In addition, the $\alpha 6 \beta 4$ integrin may function as a receptor for laminin in some cells (Lee et al., 1992). Of these, only the $\alpha 6 \beta 1$ integrin, which mediates embryonic retinal ganglion neurite outgrowth on the AeB1eB2e laminin isoform, has been shown to function in neuronal responses to laminin (de Curtis et al., 1991; Cohen and Johnson, 1991). While studies on the neuron-like cell line PC12 have identified two $\beta 1$ integrins, $\alpha 1 \beta 1$ and $\alpha 3 \beta 1$, that interact with different neurite-promoting domains in the AeB1eB2e laminin isoform (Rossino et al., 1990; Tomaselli et al., 1990), care must be exercised in extrapolating integrin function from cell lines to primary neurons. For example, rat sympathetic neurons of the superior cervical ganglion (SCG), for which PC12 cells are a model, express the $\alpha 1 \beta 1$ integrin but, unlike PC1 2 cells, do not use it as a major laminin receptor (Lein et al., 1991).

In previous work, it has been difficult to characterize integrin function in primary neurons because few $\alpha$-subunit-specific antibodies capable of recognizing rodent or avian integrins were available. In the present article, integrin expression by sensory neurons was studied biochemically in cultures of rat and mouse dorsal root ganglion (DRG) neurons. Several $\beta 1$ integrin laminin receptors were identified by immunoprecipitation in these neurons $-\alpha 1 \beta 1, \alpha 3 \beta 1$, and $\alpha 6 \beta 1$. To provide evidence for their function, a set of function-inhibiting antibodies specific for human $\alpha$-integrin subunits was used to study integrin functions in embryonic human DRG neurons. The results provide direct evidence that two of the integrins expressed by sensory neurons, $\alpha 1 \beta 1$ and $\alpha 3 \beta 1$, function in neurite outgrowth in response to laminin. In addition, our results indicate that the relative functional importance of individual laminin-binding integrins in DRG neurons depends on the subunit composition of the laminin isoform used as the substrate.

\section{Materials and Methods}

Materials. Newborn Sprague-Dawley rats and Swiss Webster mice were purchased from Bantin and Kingman (Fremont, $\mathrm{CA}$ ). $\mathrm{Na}^{125}$ I was from Amersham (Arlington Heights, IL). Protein A and Protein G coupled to Sepharose CL-4B were from Pharmacia (Piscataway, NJ). The AeB leB2e isoform of laminin was purified from the EHS sarcoma using published procedures (Kleinman et al., 1982) and was shown by SDSPAGE and protein blotting to be free of fibronectin or collagen (not shown). EHS laminin consisted of three protein bands in SDS-PAGE of $450 \mathrm{kDa}$ (Ae chain), $220 \mathrm{kDa}$ (B1e chain), and $200 \mathrm{kDa}$ (B2e chain). In addition to our own preparation of EHS laminin, a commercial preparation of EHS laminin (Collaborative Research, Lexington, MA) that was $>95 \%$ pure was also tested and gave similar results. The AmBleB2e isoform was purified in intact form by EDTA extraction of human placenta (Ehrig et al., 1990), and was purchased from Telios Inc. (La Jolla, CA). The preparation was shown by ELISA and protein blotting to contain the Am, Ble, and B2e chains, but not the Ae chain. AeBleB2e from the mouse EHS sarcoma was chosen instead of AeB1eB2e from human placenta for comparison with placental AmB1eB2e, because EHS AeB1eB2e is isolated in intact form without prior proteolysis, whereas human placental $\mathrm{AeB} 1 \mathrm{eB} 2 \mathrm{e}$ is isolated as a protcolytic fragment following pepsin digestion (Leivo and Engvall, 1988; Ehrig et al., 1990). All other chemicals were purchased from Sigma (St. Louis, MO).

Antibodies. All of the monoclonal antibodies (mAbs) were previously characterized as function-blocking antibodies. mAbs PIE6 (anti- $\alpha 2 \beta 1$; IgG1), PIB5 (anti- $\alpha 3 \beta 1$; IgG1), and PID6 (anti- $\alpha 5 \beta 1$; IgG3) have been characterized (Wayner and Carter, 1987) and were purchased as ascites from Telios Inc. (La Jolla, CA). mAbs A2B2 (anti- $\beta 1$; IgG1) and S2G3 (anti- $\alpha 1 \beta 1$; IgM) have been characterized previously (Hall et al., 1990). GoH3 (anti- $\alpha 6 \beta 1$; rat IgG2a; mouse and human reactive) was generously provided by Dr. A. Sonnenberg (Sonnenberg et al., 1988). mAb 3A3 (anti-rat $\alpha 1 \beta 1 ; \operatorname{IgG} 1$ ) IgG was a generous gift of David Turner (Turner et al., 1989). Function-blocking monoclonal antibodies were included in the human DRG cultures at the indicated concentrations: A2B2 (anti$\beta 1,50 \mu \mathrm{g} / \mathrm{ml} \mathrm{IgG}$ ), S2G3 (anti- $\alpha 1 \beta 1,75 \mu \mathrm{g} / \mathrm{ml}$ IgG), PIE6 (anti- $\alpha 2 \beta 1$, 1:500 dilution of ascites), PIB5 (anti- $\alpha 3 \beta 1,1: 500$ dilution of ascites), PID6 (anti- $\alpha 5 \beta 1,1: 500$ dilution of ascites), GoH3 (anti- $\alpha 6,50 \mu \mathrm{g} / \mathrm{ml}$ $\mathrm{IgG}$ ). Antibody concentrations used were about fivefold greater than those that were found to be maximally inhibitory in non-neuronal cell adhesion studies. For immunoprecipitations, several polyclonal antibodies were kindly provided: anti- $\alpha 3$ cytoplasmic domain (R. Hynes), anti- $\beta 1$ (V. Patel), and anti- $\beta 4$ (V. Quaranta).

Cell culture. Newborn rat and mouse DRGs were dissected into $\mathrm{Ca}^{2+}$ $\mathrm{Mg}^{++}$-free Hank's Balanced Salt Solution (HBSS; UCSF Cell Culture Facility) and incubated with $0.1 \%$ trypsin for $30 \mathrm{~min}$ at $37^{\circ} \mathrm{C}$. Ganglia were dissociated with trituration through a flame-polished Pasteur pipette in HBSS containing $10 \%$ fetal calf serum (FCS). Dissociated cells were depleted of non-neuronal cells by preplating for $1 \mathrm{hr}$ at $37^{\circ} \mathrm{C}$ in $60 \mathrm{~mm}$ tissue culture dishes in DRG growth medium consisting of Dulbecco's Modified Eagle's Medium (DMEM; $4.5 \mathrm{gm} /$ liter glucose) with $10 \% \mathrm{FCS}, 50 \mathrm{ng} / \mathrm{ml} 2.5 \mathrm{~S}$ nerve growth factor, and $100 \mathrm{U} / \mathrm{ml}$ of penicillin/streptomycin. Unattached neurons were decanted, washed once in growth medium, and plated in growth medium at about 500,000 cells $/ 35 \mathrm{~mm}$ dish precoated with $10 \mu \mathrm{g} / \mathrm{ml}$ EHS laminin. After $3 \mathrm{~d}$, cultures were treated twice for $48 \mathrm{hr}$ each with $10 \mu \mathrm{M}$ cytosine arabinoside in growth medium, followed by $24 \mathrm{hr}$ in growth medium alone. Following treatment the cultures contained $>95 \%$ neurons, as assessed using morphological criteria. Further neuronal enrichment was attained following radiolabeling of the cultures (see below).

Human tissue samples (8-12 weeks fetal age), from which dorsal root ganglia could be isolated, were obtained from the MRC Tissue Bank, Royal Marsden Hospital, London, England. Ethical approval for this work was obtained from the Ethical Committee, Guy's Hospital, London. Dorsal root ganglia were collected, trypsinized, and dissociated as previously described (Doherty and Walsh, 1989). Neurons were seeded at a density of approximately 50 neurons $/ \mathrm{mm}^{2}$ in serum-free growth medium (Bottenstein and Sato, 1978) that contained $1 \mathrm{mg} / \mathrm{ml} \mathrm{BSA}$ and $50 \mathrm{ng} / \mathrm{ml} 2.5 \mathrm{~S}$ mouse nerve growth factor. Substrates were prepared by coating eight-chamber tissue culture slides (Nunc, Naperville, IL) first with $10 \mu \mathrm{g} / \mathrm{ml}$ poly-D-lysine followed by washing in distilled water, and then with either the AeB1 eB2e isoform $(5 \mu \mathrm{g} / \mathrm{ml})$, the AmB1eB2e isoform $(5 \mu \mathrm{g} / \mathrm{ml})$, or RN22 cell-conditioned medium (CM) as described (Tomaselli et al., 1986). Neurons were cultured for $16 \mathrm{hr}$ in the presence or absence of antibodies.

PC12 cells were grown in DMEM with $4.5 \mathrm{gm} /$ liter glucose, $10 \%$ horse serum, $5 \%$ newborn calf serum, and $100 \mathrm{U} / \mathrm{ml}$ of penicillin $/$ streptomycin. PC12 cell attachment studies were performed as previously described (Tomaselli et al., 1990). RN22 cells were kindly provided by M. Manthorpe and were cultured as previously described (Tomaselli et al., 1986). Serum-free RN22 CM was prepared by culturing confluent monolayers for $3 \mathrm{~d}$ with growth medium lacking serum. RN22 CM was filtered through a $0.22 \mu \mathrm{m}$ syringe filter (Gelman Sciences, Ann Arbor, MI) prior to use.

Neuronal radiolabeling and immunoprecipitation. Sensory neurons were surface labeled by lactoperoxidase-catalyzed iodination. To one $35 \mathrm{~mm}$ dish containing about 500,000 neurons was added $2 \mathrm{mCi}$ of carrier-free $\mathrm{Na}^{125} \mathrm{I}, 100 \mu \mathrm{g}$ of lactoperoxidase, and $30 \mu \mathrm{l}$ of $0.03 \% \mathrm{H}_{2} \mathrm{O}_{2}$. After $10 \mathrm{~min}$ of gentle swirling at room temperature, the lactoperoxidase and $\mathrm{H}_{2} \mathrm{O}_{2}$ were replenished and the reaction was allowed to continue an additional $10 \mathrm{~min}$. The supernatant was removed and the plate was washed three times in HBSS containing $5 \mathrm{~mm}$ KI. The highly interconnected meshwork comprising the neurons and their processes was gently peeled from the bottom of the dish using the tip of an 18 gauge needle and transferred to a $15 \mathrm{ml}$ conical tube containing $15 \mathrm{ml}$ of HBSS with $5 \mathrm{mM} \mathrm{KI}$. This procedure afforded virtually complete separation of the neurons from the small percentage of underlying non-neuronal cells. Neurons were pelleted at $1000 \times \mathrm{g}$ for $10 \mathrm{~min}$ and the pellet was extracted in phosphate-buffered saline (PBS) containing 1\% Triton X-100 and $1 \mathrm{~mm}$ phenylmethylsulfonyl fluoride for $15 \mathrm{~min}$ on icc. Detergentinsoluble material was removed by centrifugation at $12,000 \times g$ for 15 min at $4^{\circ} \mathrm{C}$. Aliquots of the supernatant $\left(1-2 \times 10^{7} \mathrm{cpm}\right)$ were incubated with $10 \mu \mathrm{l}$ of a polyclonal antiserum or $10 \mu \mathrm{g}$ of a purified monoclonal IgG. Antibody-antigen complexes were harvested with Protein A- or Protein G-Sepharose CL4B as described previously (Tomaselli et al., 1990). Immunoprecipitated proteins were eluted by boiling for $5 \mathrm{~min}$ in SDS gel sample buffer, without reducing agents, and samples were 


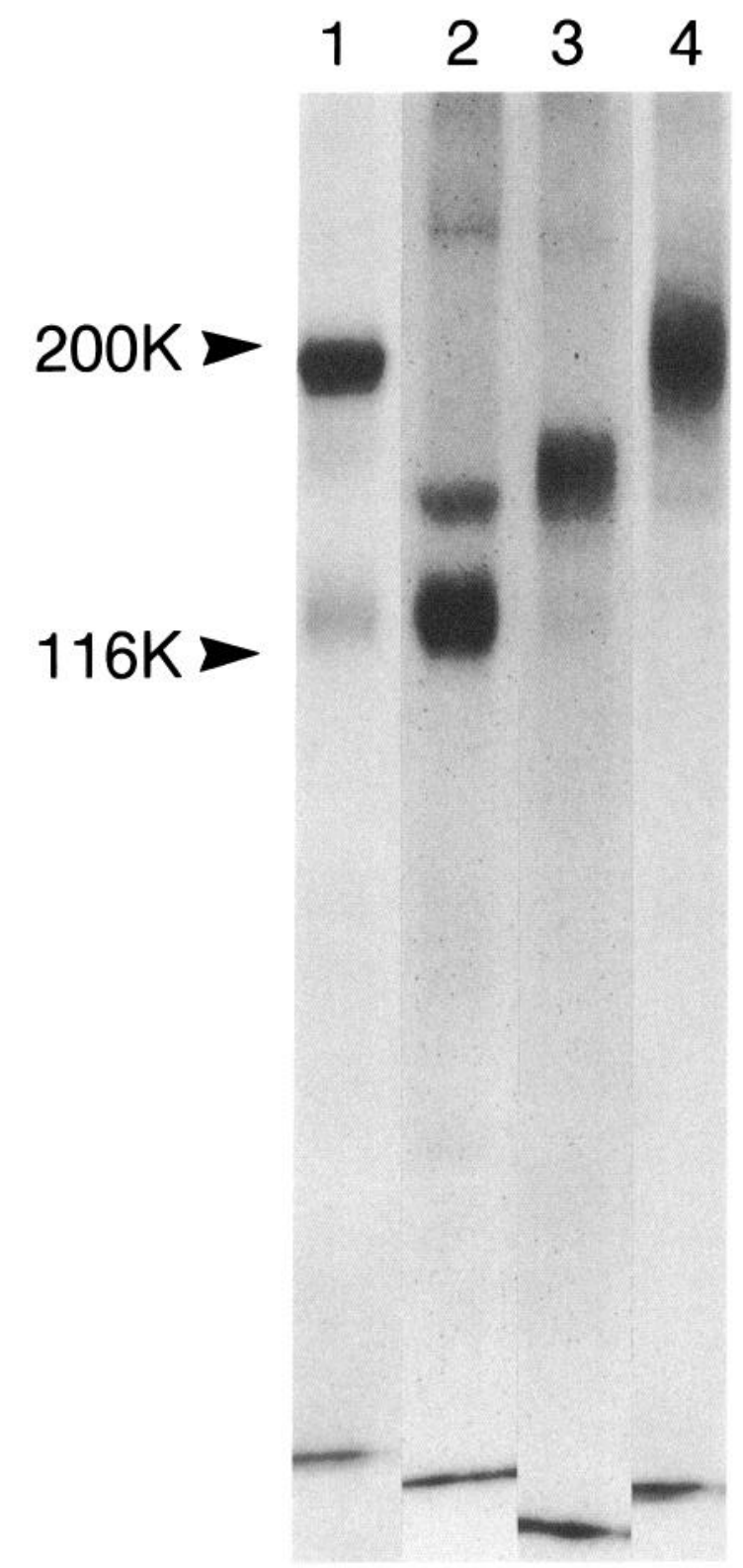

Figure 1. Immunoprecipitation of detergent extracts of surface-iodinated rat (lanes 1 and 2) and mouse (lanes 3 and 4) DRG neurons with anti- $\alpha 1$ (lane 1), anti- $\alpha 3$ (lane 2), anti- $\alpha 5$ (lane 3), and anti- $\alpha 6$ (lane 4 ). Molecular weight markers indicated by arrowheads are myosin (200K) and $\beta$-galactosidase (116K).

electrophoresed on $8 \%$ polyacrylamide slab gels according to Laemmli (1970). Gels were stained with Coomassie blue, dried, and exposed to Kodak XAR film at $-80^{\circ} \mathrm{C}$. Molecular weight markers used were myosin $(M, 200,000)$ and $\beta$-galactosidase $(M, 116,000)$.

Quantitative analysis. Neuronal cultures were fixed for $30 \mathrm{~min}$ in $4 \%$ paraformaldehyde in PBS and stained for $2-4 \mathrm{hr}$ at $4^{\circ} \mathrm{C}$ with $10 \mu \mathrm{g} / \mathrm{ml}$ DiI (Molecular Probes) in PBS. After washing once gently in PBS, slides were viewed and photographed on a Zeiss microscope using a rhodamine filter set. Fixed and stained DRG neuron cultures were scanned systematically and neurons were selected randomly for analysis. A previous study (Doherty and Walsh, 1989) demonstrated that virtually all of the cells with a neuronal morphology (large, round cell body and fine, branching processes) stain with neurofilament antibodies. Thus, neurons were easily recognized on morphological grounds. The percentage of neurons with at least one neurite equal to or greater than one cell body diameter in length was determined. Determinations were made on two sister cultures in all experiments, and at least 100 neurons were counted per culture. By systematically scanning the preparation, neurons with at least one neurite greater than one cell diameter in length were selected randomly, and the length of the single longest neurite (including its branches) was determined using a computerized image analysis system. Only neurons whose cell bodies and neurites were isolated from the small percentage $(<10 \%)$ of contaminating non-neuronal cells were selected for analysis. Attachment of PC12 cells to laminin was quantitated as described previously (Tomaselli et al., 1990).

\section{Results}

\section{Integrin expression in DRG neurons}

$\beta 1$ integrins expressed in highly purified spinal sensory neurons after 1 week in culture were analyzed by immunoprecipitation of detergent extracts of surface-iodinated cells. Due to limited species cross-reactivities of the two $\alpha$-subunit-specific monoclonal antibodies, 3A3 (anti- $\alpha 1$, rat specific) and GoH3 (anti$\alpha 6$, mouse and human specific), both rat and mouse DRG neuronal cultures were studied. It was not possible similarly to study integrin expression biochemically in the human DRG neurons due to tissue limitations. In nonreducing SDS gels, immunoprecipitations of rat or mouse DRG neuronal cultures with anti$\alpha 1$, anti- $\alpha 3$, and anti- $\alpha 5$ identified labeled proteins with the expected mobilities of the $\alpha 1 \beta 1, \alpha 3 \beta 1$, and $\alpha 5 \beta 1$ integrin dimers (Fig. 1, lanes 1-3). Immunoprecipitation with anti- $\alpha 6$ yielded a protein with the characteristic mobility of the $\alpha 6$ subunit $(140 \mathrm{~K})$, and a very weak $120 \mathrm{~K}$ protein that comigrated with the $\beta 1$ subunit (Fig. 1, lane 4 ). In addition to the $\alpha 6$ subunit, anti- $\alpha 6$ immunoprecipitated a broad band at $180-200 \mathrm{~K}$ (Fig. 1 , lane 4). This is the approximate size of the integrin $\beta 4$ subunit, which is known to associate with $\alpha 6$, but not other integrin $\alpha$-subunits. A protein of the same size was weakly immunoprecipitated with an antiserum to the human integrin $\beta 4$ subunit (not shown). Thus, the $\alpha 6$ subunit appears to be associated primarily with $\beta 4$, instead of $\beta 1$, in these sensory neurons.

\section{Integrin function in DRG neurite outgrowth on AeBleB2e}

Human neurons were used in the present study because of the availability of function-blocking $\alpha$-subunit-specific antibodies to almost all of the known human $\beta 1$ integrin receptors for laminin. Dissociated fetal human DRG neurons were cultured on poly-D-lysine-coated tissue culture plastic to which either the AeB1eB2e or AmB1eB2e isoform had been adsorbed. Individual neurons extended fine processes up to several hundred micrometers in length in $16 \mathrm{hr}$ on either substrate (Fig. 2). Both the percentage of neurons that extended neurites and the average neurite length were comparable on the two laminin isoforms (Table 1, Fig. $2 A, B$ ). A mAb to the integrin $\beta 1$ subunit almost completely inhibited neurite outgrowth on substrates coated with either laminin isoform (Fig. $2 C, D$ ). Thus, $\beta 1$ integrin receptors are required for neurite outgrowth by sensory neurons on either isoform of laminin in conditions where, because of the underlying poly-D-lysine, integrins are not required for neuronal attachment (see Tomaselli et al., 1986).

$\mathrm{mAbs}$ to each of four characterized laminin-binding $\beta 1$ integrins $-\alpha 1 \beta 1, \alpha 2 \beta 1, \alpha 3 \beta 1$, and $\alpha 6 \beta 1$-and to a fibronectinbinding integrin, $\alpha 5 \beta 1$, were tested for possible effects on DRG neurite outgrowth on each laminin isoform. On the AeB1eB2e isoform, anti- $\alpha 1 \beta 1$ showed the strongest inhibitory effect, reducing the percentage of neurons with neurites by $32 \%$ and the average neurite length by $54 \%$ (Table 1 , Figs. $2 E, 3 c$ ). Anti$\alpha 3 \beta 1$ did not decrease the percentage of neurons with neurites, but did reduce the average neurite length by $22 \%$ (Table 1, Figs. $2 G, 3 e$ ). Doubling the concentrations of either anti- $\alpha 1 \beta 1$ or anti- 

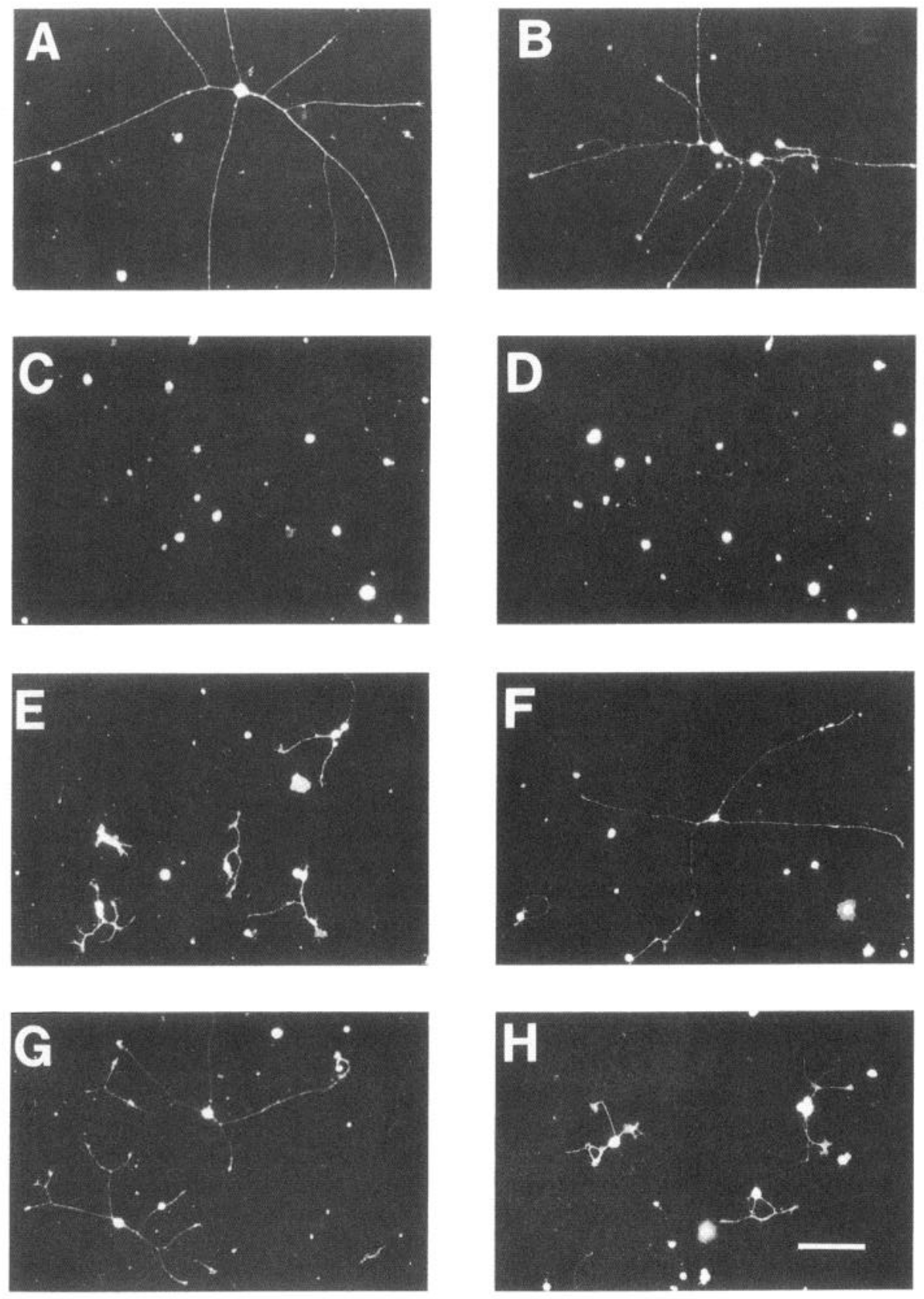

Figure 2. Differential effects of integrin $\alpha$-subunit-specific antibodies on human DRG neurite outgrowth on laminin isoforms AeB1eB2e and AmB1eB2e: fluorescent micrographs of postfixation, Dil-labeled human DRG neurons cultured $16 \mathrm{hr}$ on the AeB1eB2e $(A, C, E, G)$ or the AmBleB2e $(B, D$, $F, H)$ isoform of laminin in the absence of antibodies $(A, B)$ or in the presence of $\mathrm{mAb}$ anti- $\beta 1(C, D)$, anti- $\alpha 1 \beta 1(E$, $F)$, or anti- $\alpha 3 \beta 1(G, H)$. Antibody concentrations used are given in Materials and Methods. Scale bar, $50 \mu \mathrm{m}$. $\alpha 3 \beta 1$ failed to produce a further inhibition (not shown). Antibodies to two additional candidate laminin receptors, $\alpha 2 \beta 1$ or $\alpha 6 \beta 1$, did not have significant inhibitory effects on neurite outgrowth (Table 1). As expected, an antibody to a fibronectin receptor, $\alpha 5 \beta 1$, also did not have significant inhibitory effects. Thus, of the integrins tested, $\alpha 1 \beta 1$ and, to a lesser extent, $\alpha 3 \beta 1$ mediate neurite outgrowth on the $\mathrm{AeB} 1 \mathrm{eB} 2 \mathrm{e}$ isoform of laminin.

In previous work, where neurons have been shown to utilize more than one receptor to interact with a particular substrate, combinations of antibodies have proven to be more effective than single antibodies in inhibiting adhesion or neurite outgrowth (cf. Bixby et al., 1987; Hall et al., 1990; Tomaselli et al., 1990). Indeed, culture of neurons with antibodies to both $\alpha 3$ and $\alpha 1$ did produce a further decrease in average neurite length compared to anti- $\alpha 1$ alone (not shown). However, specificity controls, using different antibody combinations, did not yield interpretable results. The most important observation was that the combination of these two antibodies did not inhibit neurite outgrowth as completely as antibodies to the integrin $\beta 1$ subunit, suggesting that an additional $\beta 1$ integrin functions as a third laminin receptor on these neurons.

\section{Integrin function in DRG neurite outgrowth on AmBleB2e}

On the AmB1eB2e isoform, similar experiments gave distinctly different results (Table 1). Anti- $\alpha 3 \beta 1$ had a considerably stronger effect on neurite outgrowth on AmB1eB2e than on AeB1eB2e laminin, reducing the percentage of neurons with neurites by $50 \%$ (compared to $<5 \%$ on AeB1 eB2e) and the average neurite length by $53 \%$ (compared to $22 \%$ on AeB1eB2e; Figs. $2 H, 3 f$ ). In contrast to the above results on $\mathrm{AeB} 1 \mathrm{eB} 2 \mathrm{e}$, anti- $\alpha 1 \beta 1$ did not significantly reduce neurite outgrowth on the AmB1eB2e isoform (Table 1, Figs. $2 F, 3 d$ ). The failure of $\alpha 1 \beta 1$-specific 


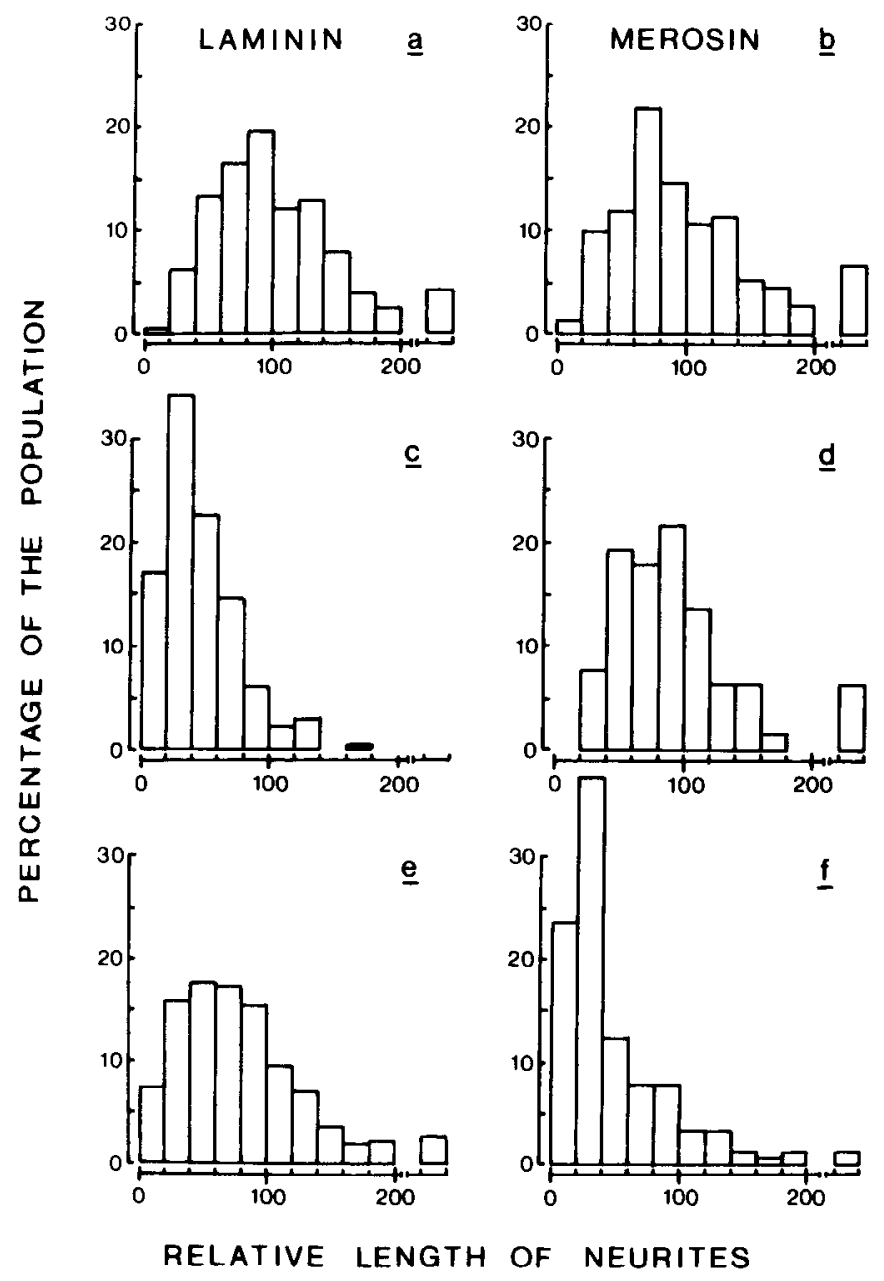

Figure 3. Neurite length histograms for human DRG neurons cultured either on $\Lambda \mathrm{eB} 1 \mathrm{eB} 2 \mathrm{e}$ laminin $(a, c, c)$ or $\mathrm{AmB} 1 \mathrm{eB} 2 \mathrm{e}$ laminin $(b, d, f)$ in the absence of antibodies $(a, b)$ or in the presence of anti- $\alpha 1 \beta 1(c, d)$ or anti- $\alpha 3 \beta 1(e, f)$. Values are normalized to average neurite length in control cultures (without added antibodies; 100 units). AeB leB2e laminin values are pooled from four experiments; AmB1eB2e laminin values are pooled from two experiments. The number of neurites measured was $a, 273 ; b, 152 ; c, 324 ; d, 130 ; e, 308$; and $f, 154$. Note that the percentage of the population with neurites of $>60$ relative units is $a$, $80.2 ; b, 76.9 ; c, 26.6 ; d, 73.1 ; e, 59.4 ;$ and $f, 26.6$.

antibodies to inhibit neurite outgrowth on AmB1eB2e-coated substrates demonstrated that the strong inhibitory effects of this antibody observed on the AeB1eB2e isoform of laminin were substrate specific. As observed on EHS laminin, neurite outgrowth on $\mathrm{AmB} 1 \mathrm{eB} 2 \mathrm{e}$ was also not significantly inhibited by function-blocking antibodies to either $\alpha 2, \alpha 6$, or $\alpha 5$.

To address the possibility that species differences, not subunit differences, account for the different properties of the two laminin isoforms, DRG neurite outgrowth was studied also on polyD-lysine substrates coated with rat KN22 cell CM. Previous work has shown that an isoform of laminin is the active neurite outgrowth factor sccreted by these cells (Davis et al., 1985; Lander et al., 1985), and recent studies have shown that the laminin isoform secreted by these cells is AmBleB2e (Engvall et al., 1992). DRG neurite outgrowth on rat RN22 cell-derived $\mathrm{AmB} 1 \mathrm{eB} 2 \mathrm{e}$ was also strongly inhibited by $\beta 1$ integrin antibodies, consistent with previous studies examining neurite outgrowth on this substrate (Tomaselli et al., 1986; Engvall et al.,
Table 1. Effects of $\alpha$-subunit-specific integrin antibodies on human
DRG neurite outgrowth on the AeB1eB2e and AmB1eB2e isoforms of laminin

\begin{tabular}{|c|c|c|}
\hline Substrate & $\begin{array}{l}\% \text { Neurons } \\
\text { with neurites }\end{array}$ & $\begin{array}{l}\text { \% Average } \\
\text { neurite length" }\end{array}$ \\
\hline \multicolumn{3}{|c|}{ Laminin AeB $1 \mathrm{eB} 2 \mathrm{e}$} \\
\hline Anti- $\beta 1$ & $4 \pm 1$ & $11 \pm 1$ \\
\hline Anti- $\alpha 1 \beta 1$ & $68 \pm 13$ & $46 \pm 7$ \\
\hline Anti- $\alpha 2 \beta 1$ & $99 \pm 4$ & $95 \pm 6$ (71) \\
\hline Anti- $\alpha 3 \beta 1$ & $96 \pm 6$ & $78 \pm 7(308)$ \\
\hline Anti- $\alpha 5 \beta 1$ & $102 \pm 6$ & $111 \pm 5$ \\
\hline Anti- $\alpha 6 \beta 1$ & $93 \pm 5$ & $99 \pm 5 \quad(146)$ \\
\hline \multicolumn{3}{|c|}{ Laminin AmBleB2e } \\
\hline Anti- $\beta 1$ & $7 \pm 1$ & $<3$ \\
\hline Anti- $\alpha 1 \beta 1$ & $103 \pm 4$ & $95 \pm 6 \quad(130)$ \\
\hline Anti- $\alpha 2 \beta 1$ & $90 \pm 5$ & $105 \pm 6 \quad(130)$ \\
\hline Anti- $\alpha 3 \beta 1$ & $49 \pm 6$ & $47 \pm 12(154)$ \\
\hline Anti- $\alpha 5 \beta 1$ & $102 \pm 6$ & $100 \pm 7(131)$ \\
\hline Anti- $\alpha 6 \beta 1$ & $100 \pm 4$ & $97 \pm 7(112)$ \\
\hline
\end{tabular}

Human DRG neurons were cultured for 16 hr on either the AeB leB2e or AmBleB2e isoform of laminin. In some cultures, mAbs were added at the concentrations specified in Materials and Methods. The percentage of neurons with at least one neurite greater than one cell body diameter in length was counted. Each value represents the mean \pm SD or range of at least two separate experiments, each with duplicate determinations. At least 100 neurons were counted per determination. The neurite length values are mean $\pm \mathrm{SD}$ or range of at least two separate experiments.

"Values are percentage of positive control (no added antibodies); on AeB1eB2e, $58 \pm 5$ (mean $\pm \mathrm{SD}, N=4$ ); on AmBleB2e, $42 \pm 2$ (mean \pm range, $N=2)$. In two experiments where the two laminin isoforms were compared directly, the percentage of neurons with neurites was comparable $(40 \pm 4$ on AeBleB2e, 41 \pm 1 on AmBleB2e).

"Values are percentage of positive control (no added antibodies); on AeBleB2e, $278 \pm 30 \mu \mathrm{m}$ (mean $\pm \mathrm{SD}, N=4$ ); on AmBleB2e, $312 \pm 45 \mu \mathrm{m}$ (mean \pm range, $N=2$ ).

Values in parentheses are the number of neurites measured.

1992). The relative effects of anti- $\alpha 1$ and anti- $\alpha 3$ on rat $\mathrm{RN} 22$ cell AmB1eB2e were similar to those observed on human placental AmB1eB2e. Anti- $\alpha 3$ had a much stronger inhibitory effect than anti- $\alpha 1$, reducing the percentage of neurons with neurites by $70 \%$, as compared to less than $5 \%$ inhibition in the presence of anti- $\alpha 1$ (Table 2). Thus, DRG neurite outgrowth in response to the AmB1eB2e isoform from two different species was similarly affected by antibodies to $\alpha 1$ or $\alpha 3$.

In order to determine whether the $\mathrm{AmB} 1 \mathrm{eB} 2 \mathrm{e}$ isoform is capable of interacting at all with the $\alpha 1 \beta 1$ integrin, we studied the effects of anti- $\alpha 1 \beta 1$ on the attachment of a rat neuronal cell line, $\mathrm{PC} 12$, to these two laminin isoforms. Previous work has shown that $\alpha 1 \beta 1$ and $\alpha 3 \beta 1$ both function in PC12 cells as receptors for the AeB1eB2e isoform (Rossino et al., 1990; Tomaselli et al., 1990). PC12 cells were allowed to attach to varying concentrations of each laminin isoform in the presence or absence of the monoclonal antibody, $3 \mathrm{~A} 3$, which is specific for the rat $\alpha 1 \beta 1$ heterodimer (Turner et al., 1989; Ignatius et al., 1990; Tawil et al., 1990). PC1 2 cell attachment to AmB leB2e was significantly inhibited by anti- $\alpha 1$, but to a lesser extent than the inhibition observed on EHS laminin (Fig. 4). At saturating substrate coating concentrations of the two laminin isoforms, inhibition by the anti- $\alpha 1 \beta 1$ was about $30 \%$ on AmB 1 eB2e compared to about $70 \%$ on $\mathrm{AeB} 1 \mathrm{eB} 2 \mathrm{e}$. Thus, there does appear to be a recognition site for $\alpha 1 \beta 1$ on the AmB1eB2e isoform, but it appears to be quantitatively less important than the corresponding site on the $\mathrm{AeB} 1 \mathrm{eB} 2 \mathrm{e}$ isoform of laminin. 
Table 2. Human DRG neurite outgrowth on RN22 cell CM: effects of integrin antibodies

$\%$ Neurons with neurites

$\begin{array}{ll}\text { Anti- } \alpha 1 \beta 1 & 96 \pm 8 \\ \text { Anti- } \alpha 3 \beta 1 & 31 \pm 10\end{array}$

Values are percentage of positive control (no added antibodies): $52 \pm 1$ (average \pm range of determinations made on duplicate cultures from a single experiment).

\section{Discussion}

The main objectives of the present study were (1) to characterize $\beta 1$ integrin expression biochemically in one neuronal population - sensory neurons of the DRG; (2) to determine, using subunit-specific antibodies, which of the expressed integrins mediate neurite outgrowth on the classical isoform of laminin (AeB1eB2e) isolated from the EHS sarcoma; and (3) to determine if the same $\beta 1$ integrins function in neurite outgrowth in response to a second laminin isoform (AmB1eB2e), which contains the Am instead of the Ae subunit. Results show that DRG neurons express several integrin heterodimers, at least two of which function as laminin receptors. Results also indicate that the functional importance of individual laminin-binding integrins depends upon the subunit composition of the isoform of laminin utilized as a substrate.

Previous work has shown that the classical isoform of laminin, containing the Ae, B1e, and B2e subunits, stimulates neurite outgrowth by many types of neurons, including avian and rodent sensory neurons (cf. Manthorpe et al., 1983; Rogers et al., 1983). $\beta 1$ integrin function has becn shown to be ncccssary for ncuronal attachment and process outgrowth in response to this isoform of laminin (Bozyczko and Horwitz, 1986; Tomaselli et al., 1986). Previous work has also shown that media conditioned by glial, muscle, endodermal, and other cells contain factors related immunologically to laminin that, when adsorbed to substrates, also function as neurite outgrowth-promoting factors (Davis et al., 1985; Lander et al., 1985). More recent work has shown that the subunit composition of the most thoroughly characterized of these factors, that secreted by rat RN22 Schwannoma cells, is $A m B 1 e B 2 e$, the same isoform of laminin present in the basal laminae of Schwann cells and skeletal myotubes (Engvall et al., 1992). $\beta 1$ integrin function has been shown to be necessary for neurite outgrowth on this isoform as well (Engvall et al., 1992).

The present study extends earlier work on the role of $\beta 1$ integrins in neuronal responses to laminin by identifying two intcgrins, $\alpha 1 \beta 1$ and $\alpha 3 \beta 1$, that function as laminin receptors on sensory neurons. This conclusion is based on the inhibitory effects of integrin-specific antibodies on neurite outgrowth. Two observations indicate that the inhibitory effects of the bivalent antibodies are specific and not due simply to antigen crosslinking. First, the effects of the antibodies were substrate specific. Thus, anti- $\alpha 1 \beta 1$ inhibited neurite outgrowth only on the AeB1eB2e isoform and not the AmB1eB2e isoform, even though the $\alpha 1 \beta 1$ integrin should have been cross-linked on either substrate. Second, bivalent antibodies to the $\alpha 5 \beta 1$ integrin, which is expressed on the surface of these neurons (Fig. 1), did not noticeably affect neurite outgrowth. Thus, as in previous studies that directly compared the inhibitory effects of monovalent and bivalent integrin antibodies (cf. Tomaselli et al., 1986), the effects observed in the present study appear not to be due to nonspecific effects of antigen cross-linking.
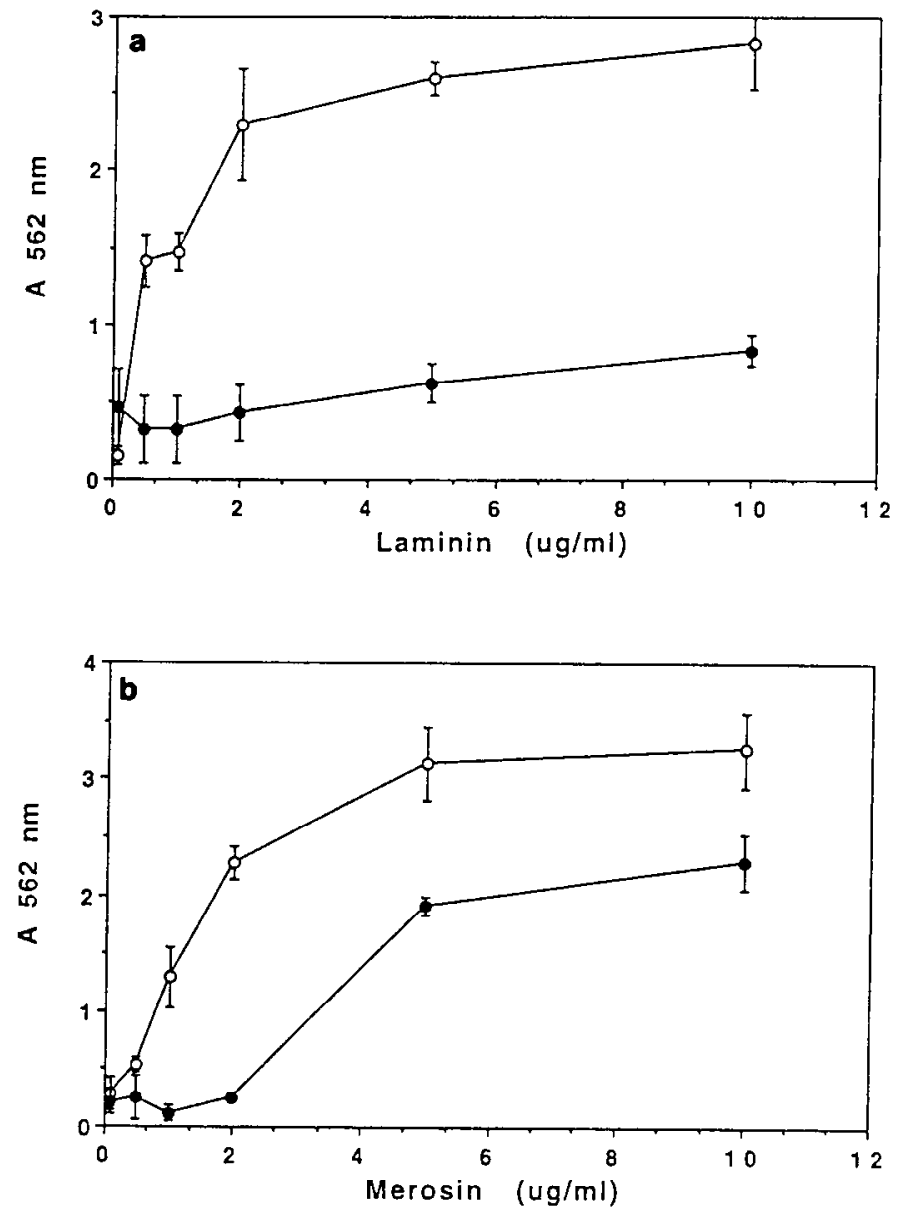

Figure 4. Effect of anti- $\alpha 1 \beta 1$ on $\mathrm{PC} 12$ cell attachment to laminins $\mathrm{AeB} 1 \mathrm{eB} 2 \mathrm{e}$ or AmBleB2e. $a, \mathrm{PCl} 2$ cell attachment to various concentrations of AeB1eB2e laminin in the absence (open circles) or in the presence (solid circles) of anti- $\alpha 1$ (mAb 3A3, $10 \mu \mathrm{g} / \mathrm{ml}) . b, \mathrm{PCl} 2$ cell attachment to various concentrations of $\mathrm{AmB} \mathrm{eB} 2 \mathrm{e}$ in the absence (open circles) or in the presence (solid circles) of anti- $\alpha 1$ (mAb $3 \mathrm{~A} 3,10 \mu \mathrm{g}$ ) $\mathrm{ml}$ ).

The $\alpha 6 \beta 1$ integrin, which has been shown to function in retinal ganglion neurite outgrowth on the $\mathrm{AeB}$ leB2e laminin isoform (de Curtis et al., 1991; Cohen and Johnson 1991), is the only $\beta 1$ integrin that has been shown to function in the outgrowth of primary neurons in response to laminin. Thus, it is interesting that it does not play a role in DRG neurite outgrowth on either laminin isoform. While the $\alpha 6$ subunit is expressed in the DRG neurons (Fig. 1), it appcars to bc associated primarily with a much larger $\beta$-subunit, most likely $\beta 4$. In other cells where $\beta 4$ is expressed, $\alpha 6$ has been shown to associate preferentially with $\beta 4$ as opposed to $\beta 1$ (Sonnenberg et al., 1990). The ligands for $\alpha 6 \beta 4$ have not been unambiguously identified. In many cells $\alpha 6 \beta 4$ appears not to function as a laminin receptor (Sonnenberg et al., 1990); however, in at least one cell type, an adenocarcinoma, it may function as a laminin receptor (Lee et al., 1992). In sensory neurons, it appears that the $\alpha 6$ subunit is not part of an effective laminin receptor, since laminin-stimulated neurite outgrowth was not sensitive to the function-blocking $\alpha 6 \mathrm{mAb}$.

The importance of $\alpha 1 \beta 1$ in mediating embryonic human DRG neurite outgrowth on EHS laminin was surprising in light of previous observations on a different class of peripheral neurons, neonatal rat sympathetic neurons. Lein et al. (1991) showed that while neonatal rat SCG neurons express the $\alpha 1 \beta 1$ integrin, it 
appears not to function in EHS laminin-mediated SCG neurite outgrowth. However, $\alpha 1 \beta 1$ does function in SCG neuronal responses to collagen. Two possible explanations for this observation are that SCG neurons express other $\beta 1$ integrins (e.g., $\alpha 3 \beta 1$ ) that function more prominently than $\alpha 1 \beta 1$ in response to laminin (Tomaselli, 1991), or that the laminin-binding ability of the $\alpha 1 \beta 1$ integrin is specifically downregulated in rat SCG neurons. Since $\alpha 1 \beta 1$ has been clearly shown to function as a laminin receptor in PC12 cells (Turner et al., 1989; Rossino et al., 1990; Tomaselli et al., 1990), which are thought to be similar functionally to rat SCG neurons, and in the human DRG neurons studied here, it seems likely that laminin recognition by the $\alpha 1 \beta 1$ integrin is downregulated in at least some classes of neurons. Precedence for this possibility is found in the cellspecific regulation of ligand recognition by the $\alpha 2 \beta 1$ integrin. This integrin functions as a collagen receptor in some cells and as a dual laminin/collagen receptor in others (Elices and Hemler, 1989; Languino et al., 1989). Since the purified receptors also exhibit different ligand-binding specificities (Kirchhofer et al., 1990), it appears that laminin recognition can be regulated independently of collagen recognition.

Our data suggest that in addition to $\alpha 1 \beta 1$ and $\alpha 3 \beta 1$, an unidentified $\beta 1$ integrin also functions as a laminin receptor on DRG neurons, since the combination of $\alpha 1$ - and $\alpha 3$-specific antibodies was less effective at inhibiting neurite outgrowth than antibodies to the $\beta 1$ subunit. At the time these experiments were performed, we believed that all candidate laminin receptors in the $\beta 1$ integrin family were being tested. Since completion of our work, a novel laminin-binding integrin, $\alpha 7 \beta 1$, has been characterized and is reported to be prominently expressed by DRG neurons (Song et al., 1992). While this receptor also seems a likely candidate to mediate DRG neurite outgrowth on laminin, this possibility was not addressed in our study.

In addition to the laminin receptors listed above, sensory neurons express several other integrin receptors. Since sensory neurons interact with two distinct domains in fibronectin, one recognized by $\alpha 5 \beta 1$ and the other by $\alpha 4 \beta 1$ (Humphries et al., 1988), they almost certainly express both fibronectin receptors. Indeed, immunocytochemical studies have shown that they express significant levels of $\alpha 5 \beta 1$ (I efcort et al., 1992). Similar studies show that they also express $\alpha 8 \beta 1$, an integrin with uncharacterized ligands (Bossy et al., 1991). Since the expression patterns within the nervous system of many integrin subunits have not yet been studied in detail, it is possible that these neurons express integrins in addition to those discussed above.

While the present study may be the most complete characterization to date of integrin expression and function in a single population of primary neurons, additional characterization is still needed. This work focused on potential laminin receptors and did not attempt to study the functions of integrins with other ligands. In addition to determining which of these integrins are also present in sensory neurons, it will be important to determine whether subpopulations of DRG neurons differ in their integrin repertoires and whether these differences influence aspects of the differentiated properties or axonal trajectories that develop in vivo. DRG neurons are not homogeneous, but instead can be divided into subpopulations based on functional modality, neurotransmitter and surface molecule expression, and neurotrophic factor responsiveness (Dodd and Jessell, 1985; Barde, 1989; Scott, 1992). Thus, heterogeneity in integrin expression among individual DRG neurons would not be surprising. Such heterogeneity could account for the partial inhib- itory effects of the $\alpha$-specific antibodies observed in this study, if, for example, individual $\alpha$-specific antibodies completely inhibited neurite outgrowth in one subpopulation while sparing another. The limited resolution of our data does not provide strong evidence for or against this possibility. Alternatively, partial antibody inhibitory effects might be due to laminin receptor redundancy on individual neurons, as has been observed in PC1 2 cells (Rossino et al., 1990; Tomaselli et al., 1990). Clearly, future studies will need to address integrin heterogeneity in subpopulations of DRG neurons.

Our study also presents evidence that different isoforms of laminin exhibit different functional properties. Previous studies have also demonstrated functional differences in neuronal responses to different laminin isoforms. For example, ciliary ganglion neurons, but not other types of neurons, interact with bacterially expressed fragments of the Bls chain (Hunter et al., 1989b). Embryonic mouse retinal ganglion neurons that have lost their ability to grow neurites on the AeB leB2e isoform maintain a $\beta 1$ integrin-dependent responsiveness to the AmBleB2e isoform (Cohen and Johnson, 1991). In neither of these two cases, however, were the differences correlated with a particular laminin receptor. Functional differences in laminin isoforms are presumably due to the effects that differences in subunit composition have on integrin binding sites. The two laminin isoforms studied here have different A-chains, Ae versus Am, while sharing the same B1 and B2 chains. Since the activity of $\alpha 1 \beta 1$ in two different cell types differed on the two isoforms, it seems likely that the A-chain plays some role in $\alpha 1 \beta 1$ recognition. Studies aimed at mapping the $\alpha 1 \beta 1$ binding site on different laminins are needed to address this issue.

The recent identifications of merosin (Am) and kallinin (Ak) mean that there are at least three different A-chain homologs. In immunocytochemistry, each has a unique distribution (Marinkovich et al., 1992). Similarly, the discoveries of S-laminin (B1s) and B1-2 increase the number of B-chain homologs to at least three. B1-2 was identified in chick where an S-laminin homolog has not yet been identified. Sequence comparison makes it unlikely that it is the chick S-laminin homolog, but that is not yet proven conclusively. The Ble and B1s subunits also have quite distinct localization patterns (Sanes et al., 1990). Finally, the recent discovery of B2t, a truncated B2 chain homolog, demonstrates that there are at least two B2-like subunits. Thus, the potential exists for 18 different trimeric isoforms of laminin, each with a distinct tissue distribution pattern. With the exception of kallinin, each of these subunits has been detected in the nervous system. This suggests that these isoforms may have quite specific roles in neural development. Precedence for restricted distribution correlating with a specific function in neural development has already been obtained for the Bls subunit, which is concentrated in the synaptic basal lamina of the neuromuscular junction (Hunter et al., 1989a). In future work, it will be important to study the functions in vitro of each laminin isoform in isolation and to examine their functions in vivo using isoform-specific perturbants or genetic methods that interfere selectively with functions of individual isoforms.

Our study utilized more than one species as a source of both the DRG neurons and the two different laminin isoforms. Embryonic human neurons were used for functional studies because a complete repertoire of function-blocking mAbs is not available for rodent integrins. Since biochemical studies were impractical with human neurons, these studies utilized rodent neurons. There was, however, good agreement between our observations on $\beta 1$ 
integrins in the two species. The $\alpha 1 \beta 1$ and $\alpha 3 \beta 1$ laminin receptors identified in rodent DRG neurons by immunoprecipitation are clearly functional in the human DRG neurons. In addition, $\alpha 6 \beta 1$, which was found not to function as a major laminin receptor in the human DRG neurons, also does not function in mouse DRG neurons (J. Cohen, personal communication). For most experiments, the two laminin isoforms were also derived from different species, mouse AeB 1eB2e or human AmB1eB2e. Even at present, there is no well-characterized source of purified, intact human AeB 1 eB2e laminin. Similarly, there is no carefully characterized preparation of purified mouse laminin containing the Am, B1e, and B2e subunits. However, there was good concordance between the human placental merosin isoform and the rat cognate derived from the RN22 Schwannoma cell line (Engvall et al., 1992). Thus, we feel it is unlikely that the functional differences we observed between the two laminin isoforms arc duc to a species difference. Potential species differences in laminin isoforms will ultimately be resolved through functional expression of different combinations of cDNAs encoding species-specific laminin subunits.

In conclusion, the present article has identified two $\beta 1$ integrins $-\alpha 1 \beta 1$ and $\alpha 3 \beta 1-$ utilized by DRG neurons to extend processes on laminin. Results also suggest that integrins may distinguish between some of the many isoforms of laminin that appear to be present in vertebrate embryos. Laminin isoforms thus may have functions that are as specific as their distributions are unique.

\section{References}

Barde Y-A (1989) Trophic factors and neuronal survival. Neuron 2:1525-1534.

Beck K, Hunter I, Engel J (1990) Structure and function of laminin: anatomy of a multidomain glycoprotein. FASEB J 4:148-160.

Bixby JL, Pratt RS, Lilien J, Reichardt LF (1987) Neurite outgrowth on muscle cell surfaces involves extracellular matrix receptors as well as $\mathrm{Ca}^{++}$-dependent and -independent cell adhesion molecules. Proc Natl Acad Sci USA 84:2555-2559.

Bossy B, Bossy-Wetzel E, Reichardt LF (1991) Characterization of the integrin $\alpha 8$ subunit: a new integrin $\beta 1$-associated subunit, which is prominently expressed on axons and on cells in contact with basal laminae in chick embryos. EMBO J 10:2375-2385.

Bottenstein JE, Sato GH (1978) Growth of a rat neuroblastoma cell line in serum-free supplemented medium. Proc Natl Acad Sci USA $76: 514-517$.

Bozyczko D, Horwitz AJ (1986) The participation of a putative cell surface receptor for laminin and fibronectin in peripheral neurite extension. J Neurosei 6:1241-1251.

Cohen J, Johnson AR (1991) Differential effects of laminin and merosin on neurite outgrowth by developing retinal ganglion cells. J Cell Sci 15:1-7.

Davis GE, Manthorpe M, Engvall E, Varon SP (1985) Isolation and characterization of a rat Schwannoma neurite-promoting factor: evidence that the factor contains laminin. J Neurosci 5:2662-2671.

de Curtis I, Quaranta V, Tamura RN, Reichardt LF (1991) Laminin receptors in the retina: sequence analysis of the chick integrin $\alpha 6$ subunit; evidence for transcriptional and posttranslational regulation. J Cell Biol 113:405-416.

Dodd J, Jessell TM (1985) Lactoseries carbohydrates specify subsets of dorsal root ganglion neurons projecting to the superficial dorsal horn of rat spinal cord. J Neurosci 5:3278-3294.

Doherty P, Walsh FS (1989) K-252a specifically inhibits the survival and morphological differentiation of NGF-dependent neurons in primary cultures of human dorsal root ganglia. Neurosci Lett 96:1-6.

Ehrig K, Leivo I, Argraves WS, Ruoslahti E, Engvall E (1990) Merosin, a tissue-specific basement membrane protein, is a laminin-like protein. Proc Natl Acad Sci USA 87:3264-3268.

Elices MJ, Hemler ME (1989) The human integrin VLA-2 is a collagen receptor on some cells and a collagen/laminin receptor on others. Proc Natl Acad Sci USA 86:9906-9910.
Engel J, Hunter I, Schulthess T, Beck K, Dixon TW, Parry DAD (1991) Assembly of laminin isoforms by triple and double standard coiledcoil structures. Biochem Soc Trans 19:839-844.

Engvall E, Earwicker D, Haaparanta T, Ruoslahti E, Sanes JR (1990) Distribution and isolation of four laminin variants: tissue restricted distribution of heterotrimers assembled from five different subunits. Cell Keg 1:731-740.

Engvall E, Earwicker D, Day A, Muir D, Manthorpe M, Paulsson M (1992) Merosin promotes cell attachment and neurite outgrowth and is a component of the neurite-promoting factor of RN22 Schwannoma cells. Exp Cell Res 198:115-123.

Gehlsen K, Dickerson K, Argraves WS, Fngvall F, Ruoslahti E (1989) Subunit structure of a laminin-binding integrin and localization of its binding site on laminin. J Biol Chem 264:19034-19038.

Hall DE, Reichardt LF, Crowley E, Holley B, Moezzi H, Sonnenberg A, Damsky CH (1990) The $\alpha 1 \beta 1$ and $\alpha 6 \beta 1$ integrin heterodimers mediate cell attachment to distinct sites on laminin. J Cell Biol 110: 2175-2184.

Hemler ME (1990) VLA proteins in the integrin family: structures, functions, and their role on leukocytes. Annu Rev Immunol 8:365400.

Humphries MJ, Akiyama SK, Komiriya A, Olden K, Yamada KM (1988) Neurite extension of chicken peripheral nervous system neurons on fibronectin. Relative importance of specific adhesion sites in the central cell-binding domain and the alternatively spliced type III connecting segment. J Cell Biol 106:1289-1298

Hunter D, Shah V, Merlie J, Sanes J (1989a) A laminin-like adhesive protein concentrated in the synaptic cleft of the neuromuscular junction. Nature 338:229-234.

Hunter DD, Porter BE, Bullock JW, Adams SP, Merlie JP, Sanes JR (1989b) Primary sequence of a motor neuron-selective adhesive site in the synaptic basal lamina protein S-laminin. Cell 59:905-913.

Ignatius MJ, Large TH, Houde M, Tawil JW, Barton A, Esch F, Carbonetto S, Reichardt LF (1990) Molecular cloning of the rat integrin $\alpha$ l-subunit: a receptor for laminin and collagen. J Cell Biol 111:709_ 720.

Kallunki P, Sainio K, Eddy R, Byers M, Kallunki T, Sariola H, Beck K, Hirvonen H, Shows TB, Tryggvason K (1992) A truncated laminin chain homologous to the $B 2$ chain: structure, spatial expression, and chromosomal assignment. J Cell Biol 119:679-693.

Kirchhofer D, Languino LR, Ruoslahti E, Pierschbacher MD (1990) $\alpha 2 \beta 1$ integrins from different cell types show different binding specificities. J Biol Chem 265:615-618.

Kleinman HK, McGarvey ML, Liotta LA, Gehron-Robey P, Tryggvason K, Martin GR (1982) Isolation and characterization of type IV procollagen, and laminin and heparan sulfate proteoglycan from the EHS sarcoma. Biochemistry 21:6188-6193.

Kramer RH, McDonald KA, Vu MP (1989) Human melanoma cells express a novel integrin receptor for laminin. J Biol Chem 264:1 564215649.

Laemmli UK (1970) Cleavage of structural proteins during the assembly of the head of bacteriophage T4. Nature 227:680-685.

Lander AD, Fujii DK, Reichardt LF (1985) Laminin is associated with the neurite outgrowth-promoting factors found in conditioned media. Proc Natl Acad Sci USA 82:2183-2187.

Languino RR, Gehlsen KR, Wayner E, Carter WG, Engvall E, Ruoslahti E (1989) Endothelial cells use the $\alpha 2 \beta 1$ integrin as a laminin receptor. J Cell Biol 109:2455-2462.

Lee EC, Lotz MM, Steele GD, Mercurio AM (1992) The integrin $\alpha 6 \beta 4$ is a laminin receptor. J Cell Biol 117:671-678.

Lefcort F, Venstrom K, McDonald JA, Reichardt LF (1992) Regulation of expression of fibronectin and its receptor $\alpha 5 \beta 1$ during development and regeneration of peripheral nerve. Development 116 : 767-782.

Lein PJ, Higgins D, Turner DC, Flier LA, Terranova VP (1991) The $\mathrm{NCl}$ domain of type IV collagen promotes axonal growth in sympathetic neurons through interaction with the alpha $1 /$ beta 1 integrin. J Cell Biol 1 13:417-428.

Leivo I, Engvall E (1988) Merosin, a protein specific for basement membranes of Schwann cells, striated muscle and trophoblast, is expressed late in nerve and muscle development. Proc Natl Acad Sci USA 85:1544-1548.

Manthorpe M, Engvall E, Ruoslahti E, Longo FM, Davis GE, Varon S (1983) Laminin promotes neurite regeneration from cultured peripheral and central neurons. J Cell Biol 97:1882-1890.

Marinkovich MP, Lunstrum GP, Keene DR, Burgeson RE (1992) The 
dermal-epidermal junction of human skin contains a novel laminin variant. J Cell Biol 119:695-703.

O'Rear JJ (1992) A novel laminin B1 chain variant in avian eye. J Biol Chem 267:20555-20557.

Reichardt LF, Tomaselli KJ (1991) Extracellular matrix molecules and their receptors: functions in neural development. Annu Rev Neurosci $14: 531-570$.

Rogers SL, Letourneau PC, Palm SL, McCarthy J, Furcht LT (1983) Neurite expansion by peripheral and central nervous system neurons in response to substratum-bound fibronectin and laminin. Dev Biol 98:212-220.

Rossino P, Garazzi I, Timpl R, Aumaillely M, Abbadini M, Giancotti F, Silengo L, Marchisio P, Tarone G (1990) Nerve growth factor induces increased expression of a laminin-binding integrin in rat pheochromocytoma PC12 cells. Exp Cell Res 189:100-108.

Sanes JR, Engvall E, Butkowski R, Hunter DD (1990) Molecular heterogeneity of basal laminae: isoforms of laminin and collagen IV at the neuromuscular junction and elsewhere. J Cell Biol 111:16851699 .

Scott SA (1992) Sensory neurons: diversity, development, and plasticity. New York: Oxford UP.

Song WK, Wang W, Foster RF, Bielser DA, Kaufman SJ (1992) H36. $\alpha 7$ is a novel integrin alpha chain that is developmentally regulated during skeletal myogenesis. J Cell Biol 117:643-657.

Sonnenberg A, Modderman PW, Hogervorst F (1988) Laminin receptor on platelets is the integrin VLA6. Nature 336:487-489.

Sonnenberg A, Linders CJT, Modderman PW, Damsky CH, Aumaillcy
A, Timpl $\mathbf{R}$ (1990) Integrin recognition of different cell-binding fragments of laminin (P1, E3, E8) and evidence that $\alpha 6 \beta 1$ but not $\alpha 6 \beta 4$ functions as a major receptor for fragment E8. J Cell Biol 110: 2145-2156.

Tawil NJ, Houde M, Blacher R, Esch F, Reichardt LF, Turner DC, Carbonetto $S$ (1990) $\alpha 1 \beta 1$ integrin heterodimer functions as a dual laminin/collagen receptor in neural cells. Biochemistry 29:6540-6544.

Tomaselli K (1991) $\beta 1$ integrin-mediated neuronal responses to extracellular matrix proteins. Ann NY Acad Sci 633:100-104.

Tomaselli KJ, Reichardt LF, Bixby JL (1986) Distinct molecular interactions mediate neuronal process outgrowth on non-neuronal cell surfaces and extracellular matrices. J Cell Biol 103:2659-2672.

Tomaselli KJ, Damsky CII, Reichardt LF (1988) Purification and characterization of mammalian integrins expressed by a rat neuronal cell line (PC12): evidence that they function as $\alpha / \beta$ heterodimeric receptors for collagen IV and laminin. J Cell Biol 107:1241-1252.

Tomaselli KJ, Hall DE, Flier LA, Gehlsen KR, Turner DC, Carbonetto $S$, Reichardt LF (1990) A neuronal cell line ( $\mathrm{PC1}$ 2) expresses two $\beta 1$-class integrins $-\alpha 1 \beta 1$ and $\alpha 3 \beta 1$-that recognize different neurite outgrowth-promoting domains in laminin. Neuron 5:651-662.

Turner DC, Flier LA, Carbonetto S (1989) Identification of a cellsurface protein involved in PC12 cell-substratum adhesion and neurite growth on laminin and collagen. J Neurosci 9:3287-3296.

Wayner EA, Carter WG (1987) Identification of multiple cell adhesion receptors for collagen and fibronectin in human fibrosarcoma cells possessing unique $\alpha$ and common $\beta$ subunits. J Cell Biol 105:18731884. 